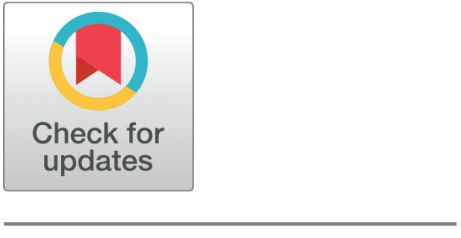

OPEN ACCESS

Received: 26.09.2021

Accepted: 19.01.2022

Published: 05.02.2022

Citation: Katuru A, Banda SR, Narayana YV, Kadire S (2022) Corner Defected Multi-Resonance Ultra-Wideband Rectangular Patch Antenna. Indian Journal of Science and Technology 15(4): 175-183. http s://doi.org/10.17485/IJST/v15i4.1800

* Corresponding author.

anjikaturu@gmail.com

Funding: None

Competing Interests: None

Copyright: @ 2022 Katuru et al. This is an open access article distributed under the terms of the Creative Commons Attribution License, which permits unrestricted use, distribution, and reproduction in any medium, provided the original author and source are credited.

Published By Indian Society for Education and Environment (iSee)

ISSN

Print: 0974-6846

Electronic: 0974-5645

\section{Corner Defected Multi-Resonance Ultra-Wideband Rectangular Patch Antenna}

\author{
Anjaneyulu Katuru ${ }^{1 *}$, Srinivas Raja Banda ${ }^{2}$, Y Venkata Narayana ${ }^{3}$, \\ Sumalatha Kadire ${ }^{4}$ \\ 1 Professor, Department of ECE, Narasaraopeta Engineering College, Narasaraopet, A.P, India \\ 2 Professor, Department of ECE, Godavari Inst. Of Eng. \& Tech, Rajahmundry, A.P, India \\ 3 Professor, Department of ECE, Tirumala Engineering College, Jonnalagadda, A.P, India \\ 4 Associate Professor, Department of ECE, Malla Reddy Engineering College for women, \\ Telangana, India
}

\section{Abstract}

Objectives: The main objective of this article is to present a novel corner defected ultra wideband (UWB-3.1 to $10.6 \mathrm{GHz}$ ) rectangular patch with a partial ground plane to enhance the bandwidth with multi-resonance characteristics. By defecting the corners, the original rectangle patch will be converted into defected shape of proposed one to satisfy the objective. Methods: A FR-4 substrate with height $(\mathrm{h})$ of $1.6 \mathrm{~mm}$, dielectric constant $\left(\varepsilon_{r}\right)$ of 4.3 and the loss tangent of 0.025 was used to develop the required antenna. The antenna was excited by a $50 \mathrm{Ohm}$ microstrip line. This antenna was designed, simulated and analyzed by using MS-CST (Microwave Studio - Computer Simulation Technology) to attain the outcomes such as return loss (S11<-10 dB), voltage standing wave ratio (VSWR $<2$ ), improved gain, Omni-directional radiation patterns, and enhanced bandwidth. Findings: It exhibits a fractional bandwidth (FBW) of $152.9 \%$ between $2 \mathrm{GHz}$ and $15 \mathrm{GHz}$. The antenna resonates at multiple frequencies owing to truncation of corners and produces resonant frequencies of $3.87 \mathrm{GHz}$ and $11.36 \mathrm{GHz}$ with the corresponding return losses of -26.03 $\mathrm{dB}$ and $-34.87 \mathrm{~dB}$ respectively in the simulation point of view. The antenna was fabricated and tested. The measured and simulated results of the desired antenna were compared, and they show good agreement. Applications: The proposed antenna is suitable for UWB, WiMAX (Worldwide Interoperability for Microwave Access), $C$ and $X$ - band communications.

Keywords: Ultrawideband; Rectangular patch; Bandwidth; Return loss; VSWR; Gain

\section{Introduction}

The Federal Communications Commission (FCC) had released the unlicensed frequency band, 3.1-10.6 GHz (7.5 GHz spectrum) for ultra-wideband (UWB) communication systems in Feb.14, 2002 ${ }^{(1)}$. One of the main challenges in designing of a compact patch antenna in UWB communication systems is to miniaturize the antennas 
with wide impedance bandwidth while still maintaining high radiation efficiency throughout the complete operating frequency band. Microstrip patch antennas are the most useful structures due to low cost, low profile, ease of fabrication \& implementation, and conformability to host surfaces i.e. planar and non-planar. One of the key drawbacks of patch antennas is their narrow bandwidth ${ }^{(2)}$. Therefore, for some of the wireless applications such as satellite communications; it is desirable to enhance the impedance bandwidth without affecting the performance of patch is a crucial task for researchers. Different bandwidth enhancement techniques have been presented in the literature; some of them are applied to radiating element or ground plane or some to both. A rectangular UWB patch with defected ground structure was presented in ${ }^{(3)}$. In this, the upper corners of the patch are square notched and lower corners are rectangular notched to enhance the bandwidth. This antenna produced a bandwidth of 3.5-14.9 GHz with percentage bandwidth of $123.91 \%$. A UWB rectangular patch with defected ground structure (DGS) was addressed in ${ }^{(4)}$. The bandwidth of this antenna could be increased by one round cut at each corner of the patch with one slot in the ground plane. This antenna provided a BW of 3.42-11.7 GHz. ${ }^{(5)}$, a rectangular UWB antenna, which is capable of supporting wide BW of 3-10.26 GHz by adding suitable slits and slots in the patch and ground, was proposed. An antenna for wireless applications was introduced in ${ }^{(6)}$ which was also acted as UWB antenna by providing a polygonal slot in the plane of ground. The enhancement of BW can be achieved in ${ }^{(7)}$ by utilizing CMA (Characteristic Mode Analysis) technique along with the structure of defected ground. The bandwidth of an antenna can also be increased by using a circular patch with a defective structure of ground ${ }^{(8)}$. Multiband operation can be attained by the octagonal patch with a slot ${ }^{(9)}$. UWB can also be implemented by semi-circular patch with fractal and defected ground ${ }^{(10)}$. A pentagonal patch with DGP (defected ground plane) was invented for ultra wideband ${ }^{(11)}$.

A UWB patch antenna for C, X- band and for improving the BW was addressed in ${ }^{(12)}$. A rectangular patch was built for WLAN and WiMAX in ${ }^{(13)}$, which was also meant for enhancing the BW by introducing slot and notches in the patch. Gap coupling is the technique used for improving the impedance $\mathrm{BW}$ of a patch ${ }^{(14)}$. A wearable $\mathrm{U}$ shaped patch was designed for the applications of C, WLAN and HIPERLAN/2 ${ }^{(15)}$. UWB and multi-wireless applications were attained by a circular patch with a slot ${ }^{(16)}$. An ultra-wideband slotted hexagonal antenna for BW enhancement was described in ${ }^{(17)}$. The operation of UWB was depicted by a stacked patch ${ }^{(18)}$ and decagonal patch ${ }^{(19)}$. In ${ }^{(20)}$, a broadband patch was represented, and increase in bandwidth could be obtained by cutting two circular slots on the patch and truncating the corners of the square patch. An M \& A - shaped radiating patches with modified ground by cutting rectangular slots ${ }^{(21,22)}$, a compact modified rectangular patch and a planar antenna with modified patch and defected ground plane $e^{(23,24)}$ were addressed for UWB communications. A corner truncated patch with slotted ground ${ }^{(25)}$ can also enhance the impedance bandwidth.

In this paper, the proposed antenna not only satisfies both UWB and BW enhancement but also yields multiple resonant characteristics at various frequencies in the measured point of view. The idea of designing of this antenna is derived from ${ }^{(3,4)}$. In this context, the upper edge corners are square truncated and lower edge corners are arc truncated to provide the larger bandwidth with multi-resonance properties. The papers reported in the above survey of literature did not enhance the bandwidth more than $11.4 \mathrm{GHz}$ while the proposed one demonstrates a FBW of $152.9 \%$ lies between 2 and $15 \mathrm{GHz}$. And it can be employed for UWB, WiMAX, C and X-band applications.

\section{Design and Geometry of Antenna}

The schematic representation and procedure of evaluation of corner defected patch (CDP) is depicted from Figure 1 a-f. In this work a rectangular patch having the volume of $\left(\mathrm{L}_{p} \mathrm{~mm} \times \mathrm{W}_{p} \mathrm{~mm} \times \mathrm{tp} \mathrm{mm}\right)$ was designed on top of the substrate with the dimensions of $\left(\mathrm{L}_{s} \mathrm{~mm} \times \mathrm{W}_{s} \mathrm{~mm} \times \mathrm{h} \mathrm{mm}\right)$, where $\mathrm{Lp}=$ Length of the rectangular patch, $\mathrm{W}_{p}=$ Width of the patch, $\mathrm{tp}=$ Thickness of the patch, $\mathrm{L}_{s}=$ Length of the substrate, $\mathrm{W}_{s}=$ Width of the substrate and $\mathrm{h}=$ Height of the substrate. The CDP was fed by a microstrip line has an area of ( $\mathrm{Lf} \mathrm{mm} \times \mathrm{Wf} \mathrm{mm}$ ), where $\mathrm{Lf}=$ Length of the feed line and $\mathrm{Wf}=$ Width of the feed line. A partial ground plane, $\mathrm{Lg} \mathrm{mm} \times \mathrm{Wg} \mathrm{mm}$, was printed in the rare side of the substrate. Where $\mathrm{Lg}=\mathrm{Length}$ of the ground plane and $\mathrm{Wg}=$ width of the ground plane. The top corners of $(\mathrm{x} \mathrm{mm} \times \mathrm{y} \mathrm{mm})$, where $\mathrm{x}=$ Horizontal length of top corners notch and $\mathrm{y}=$ Vertical length of top corners notch and $\mathrm{x}=\mathrm{y}=2.5 \mathrm{~mm}$, and the bottom corners of radius 'a' mm were etched. All these parameter values are shown in below Table 1. Figure 1 (e) shows the configuration and dimensions of the desired antenna, which is fabricated on lossy FR-4 substrate with relative permittivity of $\varepsilon_{r}=4.3$, permeability of $\mu_{r}=1$, loss tangent of Tan $\delta$ $=0.025$ and the thickness of the substrate of $\mathrm{h}=1.6 \mathrm{~mm}$. The shape and dimensions of this antenna is based on the antennas presented in ${ }^{(3,4)}$. The antenna is designed at the design frequency of $\mathrm{f}_{o}=8.5 \mathrm{GHz}$.

The basic rectangular patch is designed by using the following formulae as

$$
W_{p}=\frac{c}{2 f_{o}} \sqrt{\frac{2}{\varepsilon_{r+1}}}
$$


Where $\mathrm{W}_{p}=$ Width of the rectangular patch, $\mathrm{f}_{o}=$ Design frequency $\varepsilon_{r}=$ Relative permittivity of the dielectric.

The effective di-electric constant $\left(\varepsilon_{e}\right)$ of the dielectric (FR- 4$)$ is given by

$$
\varepsilon_{e}=\frac{\varepsilon_{r}+1}{2}+\frac{\varepsilon_{r}-1}{2}\left[\frac{1}{\sqrt{1+12 \frac{h}{W_{p}}}}\right]
$$

Where $\mathrm{h}=$ Height of the substrate, and.

$$
\left(1<\varepsilon_{e}<\varepsilon_{r}\right)
$$

The actual length $\left(\mathrm{L}_{p}\right)$ of the rectangular patch can be determined by

$$
\begin{gathered}
L_{p=} \frac{c}{2 f_{o} \sqrt{\varepsilon_{e}}}-2 \triangle L_{p} \\
\left(\triangle L_{p}\right)=0.412 h \frac{\left(\varepsilon_{e}+0.3\right)\left(\frac{W_{p}}{h}+0.264\right)}{\left(\varepsilon_{e}-0.258\right)\left(\frac{W_{p}}{h}+0.8\right)}
\end{gathered}
$$

Where $\Delta \mathrm{L}_{p}=$ Extended incremental length of the patch. $\Delta \mathrm{L}_{p}$ can be calculated by

The effective length $\left(\mathrm{L}_{e}\right)$ of the patch can be computed by

$$
L_{e}=L_{p}+2 \triangle L_{p}
$$

For the dominant mode $\left(\mathrm{TM}_{010}\right)$, the design frequency of rectangular patch is expressed as

$$
\left(f_{o}\right)_{010}=\frac{c}{2\left(L_{p}+2 \triangle L_{p}\right) \sqrt{\varepsilon_{e}}}
$$

Table 1. Parametric Dimensions of Antenna

\begin{tabular}{ll}
\hline Parameter & Value(mm) \\
\hline $\mathrm{L}_{s}$ & 35 \\
$\mathrm{~W}_{s}$ & 30 \\
$\mathrm{~h}$ & 1.6 \\
$\mathrm{~L}_{p}$ & 14.5 \\
$\mathrm{~W}_{p}$ & 15 \\
$\mathrm{tp}$ & 0.1 \\
$\mathrm{Lf}$ & 13.5 \\
$\mathrm{Wf}$ & 3.2 \\
$\mathrm{Lg}$ & 12.5 \\
$\mathrm{Wg}$ & 30 \\
$\mathrm{x}$ & 2.5 \\
$\mathrm{y}$ & 2.5 \\
$\mathrm{a}$ & 2.8 \\
\hline
\end{tabular}

\section{Results and Discussion}

\subsection{Discussion of simulation results}

The plain structure of antenna shown in Figure 1 a resonates at the frequency $3.95 \mathrm{GHz}$ and the corresponding return loss (RL) and VSWR are $-18.6 \mathrm{~dB}$ and 1.2. This structure operates in the frequency range of 3.1-11.1 GHz. The top left corner defected 
structure is shown in Figure $1 \mathrm{~b}$, for which $\mathrm{f}_{o}=4.1 \mathrm{GHz}$, and $-18.5 \mathrm{~dB}$ and 1.2 are the RL and VSWR at design frequency. It provides the BW of $7.9 \mathrm{GHz}(3.2-11.1 \mathrm{GHz})$. In addition to top left corner, the top right corner defected antenna is shown in Figure 1c, which produces the resonant frequency of $4.2 \mathrm{GHz}$ and it's $\mathrm{S}_{11}$ and VSWR are $-19.3 \mathrm{~dB}$ and 1.2. This design almost produced the same BW as the previous structure. Besides the top corners, the lower left corner is arc defected is shown in Figure 1d. The resonant frequency, $\mathrm{S}_{11}$, VSWR and bandwidth of this antenna are $6.9 \mathrm{GHz},-61.5 \mathrm{~dB}, 1.001 \mathrm{and} 8.9 \mathrm{GHz}$ (3.2-12.1 GHz). The desired antenna is shown Figure 1e. This antenna has been presented $\mathrm{S}_{11}=-33.9 \mathrm{~dB}, \mathrm{VSWR}=1.04$ at the resonant frequency of $11.3 \mathrm{GHz}$. The antenna is operating in the frequency band of $3.1 \mathrm{GHz}$ to $14.6 \mathrm{GHz}(\mathrm{BW}=11.5 \mathrm{GHz})$ which includes UWB, C band (4-8 GHz) and X-band (8-12.4 GHz). This antenna provides a larger BW and is operating at dual bands i.e. at $3.87 \mathrm{GHz}$ (Wi-MAX) and $11.36 \mathrm{GHz}$ (Satellite down link) frequencies. A partial ground plane is shown in Figure $1 \mathrm{f}$ is used for all the designs. These results are shown in Figure $2 \mathrm{a} \& \mathrm{~b}$. All the simulated results of evaluation structures of patch are tabulated in Table 2. The simulation and measured results of proposed antenna are shown in Table 3. From this comparison, it is concluded that the desired antenna produces a peak gain of $4.69 \mathrm{~dB}$, larger BW in addition to UWB characteristics.

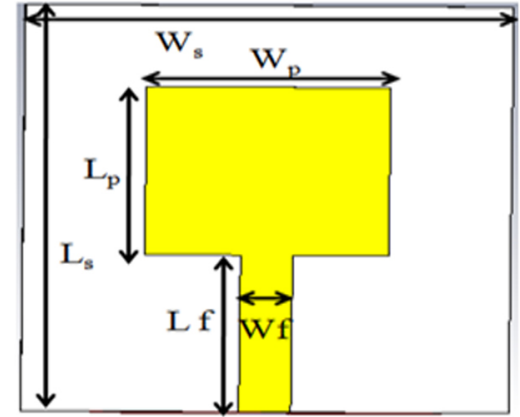

(a)

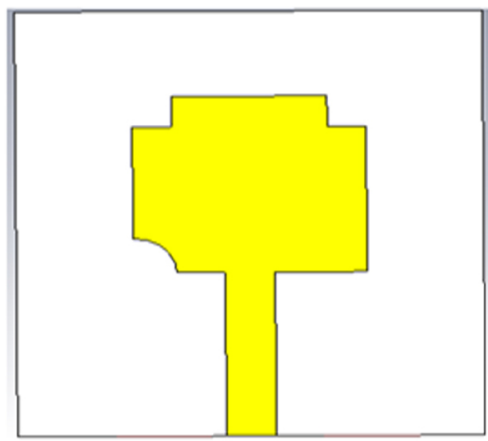

(d)

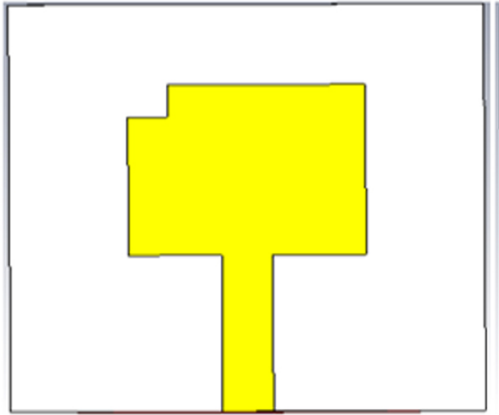

(b)

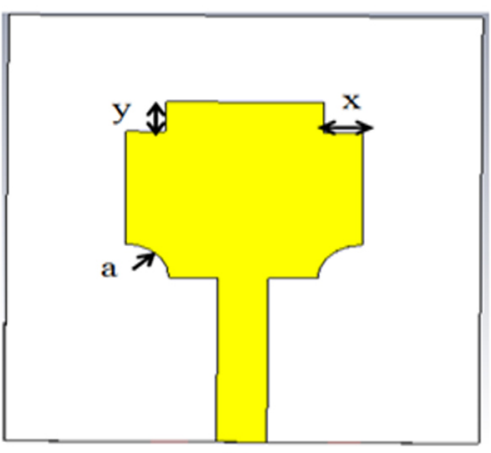

(e)

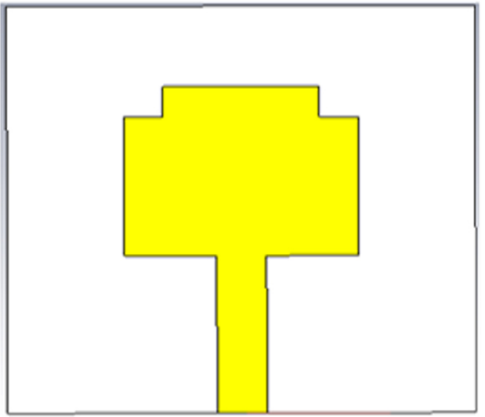

(c)

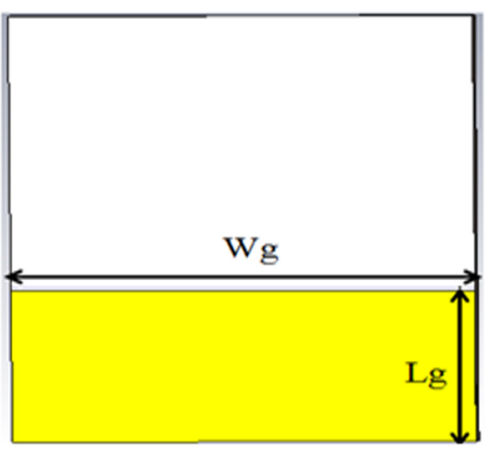

(f)

Fig 1. (a) Design-1(b) Design-2 (c) Design-3 (d) Design-4 (e) Design-5 (Proposed) (f). Partial ground plane (Bottom view).
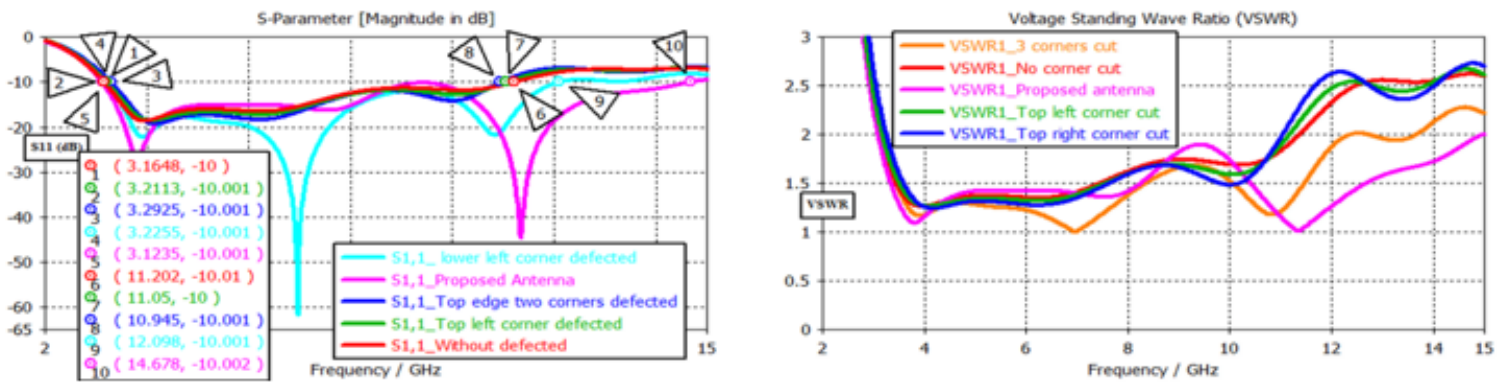

Fig 2. (a) Return loss plots for all designs (b). VSWR plots for all designs 
Table 2. Comparison of simulation results for evaluation structures

\begin{tabular}{llllll}
\hline Antenna & Resonant Freq. $(\mathbf{G H z})$ & $\mathbf{S 1 1}(\mathbf{d B})$ & VSWR & BW(GHz) & Gain at 8.5 GHz \\
\hline Design 1 & 3.9 & -18.6 & 1.2 & $3.1-11.1$ & 4.48 \\
Design 2 & 4.1 & -18.5 & 1.2 & $3.2-11.1$ & 4.86 \\
Design 3 & 4.2 & -19.3 & 1.2 & $3.2-11$ & 4.66 \\
Design 4 & 6.9 & -61.5 & 1.001 & $3.2-12.1$ & 4.84 \\
Design 5 & 3.8711 .36 & $-26.03-34.87$ & 1.04 & $3.1-14.6$ & 4.69 \\
\hline
\end{tabular}

Table 3. Simulated \& Measured results of proposed antenna

\begin{tabular}{lll}
\hline Parameter & Simulated & Measured \\
\hline S11 $(\mathrm{dB})$ & -34.87 & -37 \\
VSWR & 1.04 & 1.1 \\
Operating range $(\mathrm{GHz})$ & $3.1-14.6$ & $2-15$ \\
BW $(\mathrm{GHz})$ & 11.5 & 13 \\
Peak Gain $(\mathrm{dB})$ & 4.69 & 3.98 \\
Resonant Frequency $(\mathrm{GHz})$ & 11.3 & 7.8 \\
Radiation patterns & Omni-directional & Omni-directional \\
\hline
\end{tabular}

\subsection{Radiation patterns \& Surface current distribution}

The three-dimensional gain patterns and polar plots of $\mathrm{E} \& \mathrm{H}$ plane patterns at 6, 9 and $10.5 \mathrm{GHz}$ frequencies are shown from Figure $3 \mathrm{a}-\mathrm{f}$, from these patterns the proposed antenna radiates nearly Omni-directional patterns. The distribution of surface current at 6, 9 and $10.5 \mathrm{GHz}$ are shown in Figure $4 \mathrm{a}-\mathrm{c}$. The electromagnetic signals are radiating from edges of the patch and ground plane. The maximum values of surface current are $50.1,46.2$ and $62.1 \mathrm{~A} / \mathrm{m}$ for 6,9 and $10.5 \mathrm{GHz}$ frequencies respectively. It is evident from Figure. 4 that strong current distribution is observed along the edges of the patch and the ground plane and the current flow is dominant on the feed line also. The maximum current observed at the higher frequencies only but not at lower frequencies.

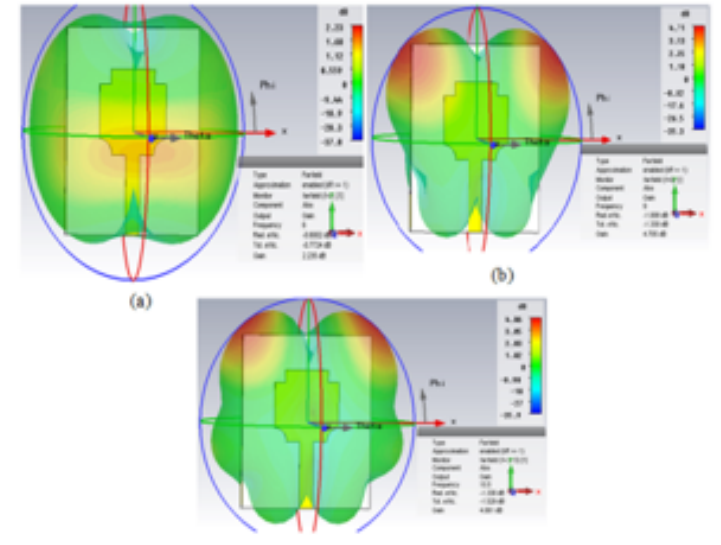

(c)

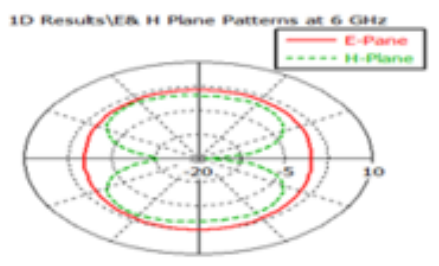

(d)

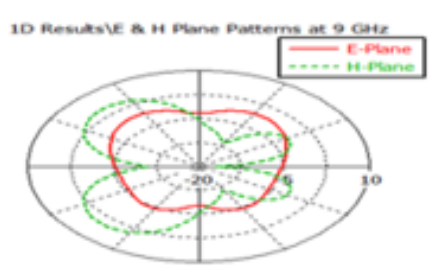

(e)

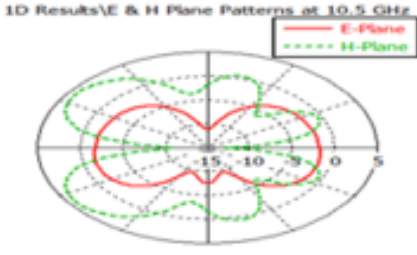

(f)

Fig 3. Three-dimensional gain pattern at (a) $6 \mathrm{GHz}$, (b) $9 \mathrm{GHz}$ (c) $10.5 \mathrm{GHz}$ frequencies. Polar E-plane and H-plane patterns at (d) 6, (e) 9 , (f) $10.5 \mathrm{GHz}$ frequencies respectively 


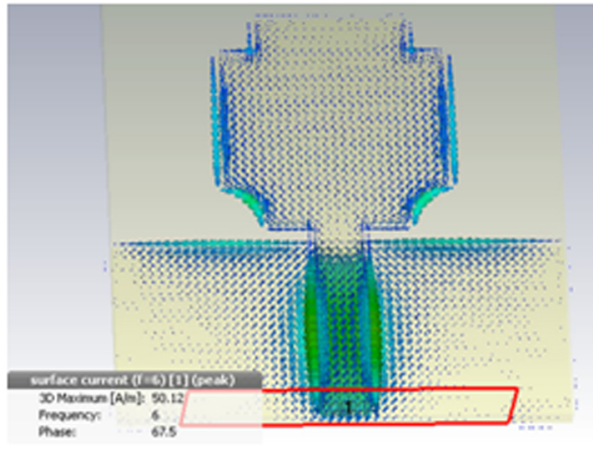

(a)
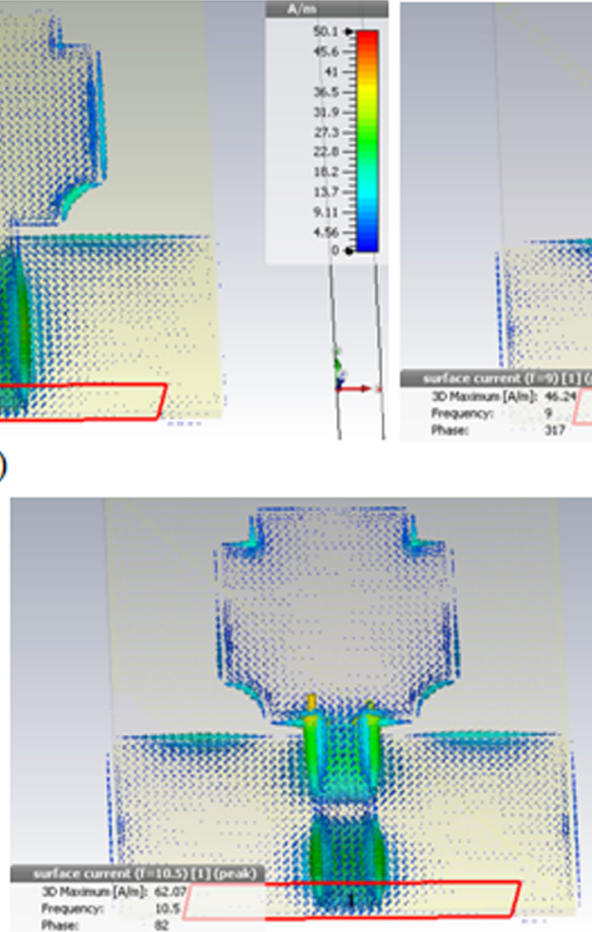

(c)

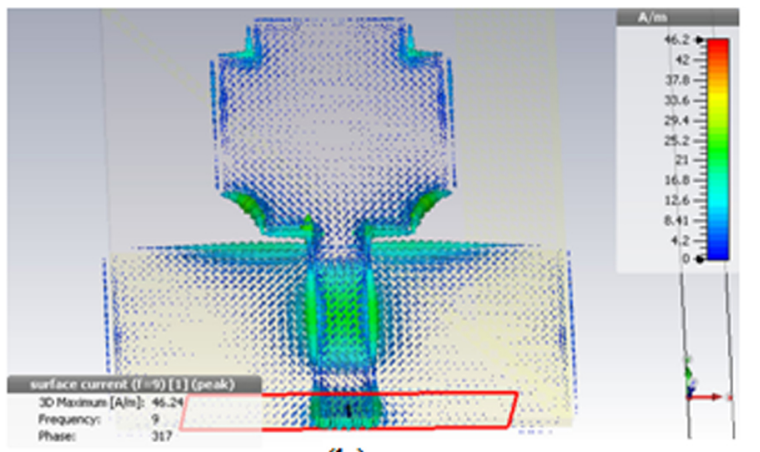

(b)

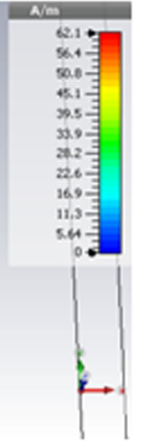

Fig 4. Simulated surface current distribution at (a) $6 \mathrm{GHz}$,(b) $9 \mathrm{GHz} \&$ (c) $10.5 \mathrm{GHz}$ frequencies.

\subsection{Experimental results and discussion}

A vector network analyzer is utilized to measure the performance of the desired antenna such as return loss, VSWR, and impedance BW. An anechoic chamber is used to measure the radiation patterns. The prototype of the fabricated antenna was under testing is represented in Figure 5. The measured return loss and VSWR of the desired antenna are shown in Figure 6 a $\&$ b. It was observed from Figure 6 that the measured return loss is less than $-10 \mathrm{~dB}$ and VSWR less than 2, which show a good agreement with the simulated results as shown in Figure 2. From the measured return loss plot, it is identified that the antenna resonates at multiple frequencies. The fabricated antenna provides a measured $\mathrm{BW}$ of $13 \mathrm{GHz}(2-15 \mathrm{GHz})$, which covers a whole ultra-wideband (3.1-10.6 GHz), Wi-MAX (3.87 GHz), C band (4-8 GHz), X-band (8-12 GHz) and lower part of the $\mathrm{K}_{u}$ band $(12-15 \mathrm{GHz})$. Figure $7 \mathrm{a}-\mathrm{c}$ show the measured polar far-field gain patterns in vertical $(\mathrm{E})$ and horizontal $(\mathrm{H})$ plane patterns at 6,9 and $10.5 \mathrm{GHz}$ frequencies respectively. It is observed that the antenna produced a nearly good Omni-directional patterns at all frequencies in the vertical and horizontal planes. These patterns, as expected, are suitable for UWB, WiMAX, C, X and $\mathrm{K}_{u}$ band applications.

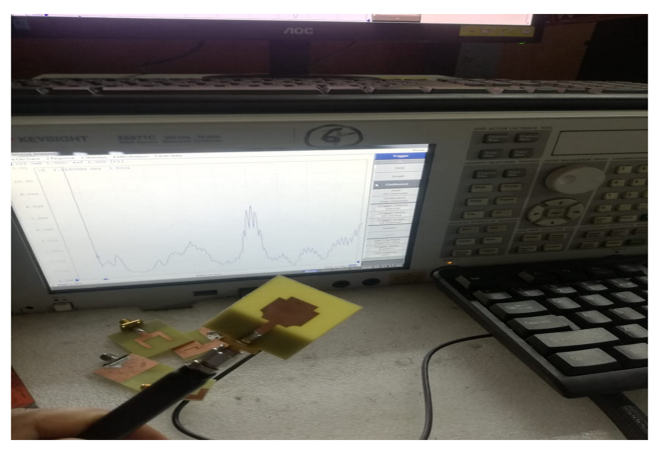

Fig 5. Fabricated antenna prototype in testing. 


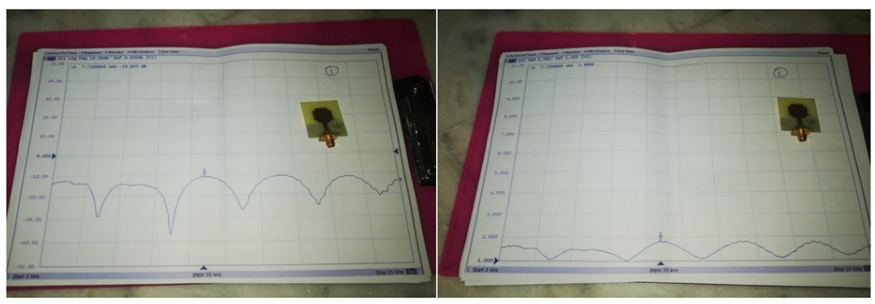

Fig 6. (a). Measured Return loss (dB); (b). Measured Voltage standing wave ratio (V.S.W.R)

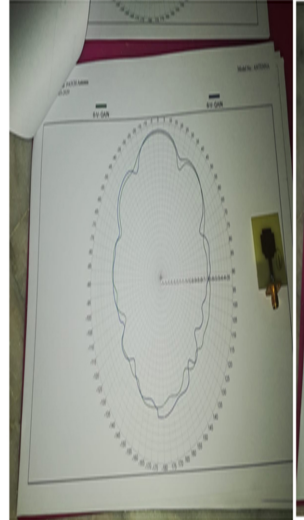

(a)

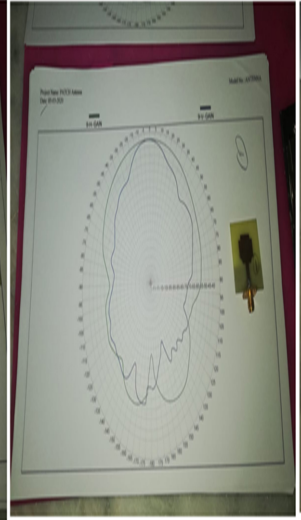

(b)

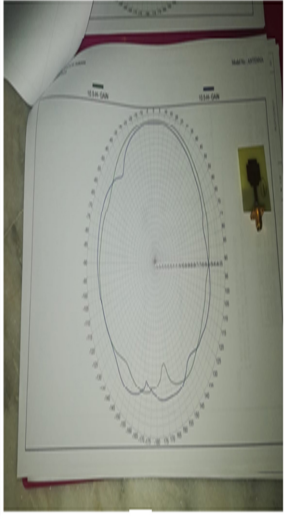

(c)

Fig 7. Measured gain patterns at(a) 6 (b) 9 (c) 10.5 GHzfrequencies

Gain is an essential parameter in the design of ultra-wideband antenna. The simulated peak gain is $4.69 \mathrm{~dB}$ and measured peak gain is $3.98 \mathrm{~dB}$. The proposed antenna was compared to some of the references in literature as shown in Table 4 . The desired antenna has been produced an absolute BW of $13 \mathrm{GHz}$ and fractional BW of $152.9 \%$, which is the highest of all existing ones in the literature. By means of arc truncation in the lower edge corners of the patch, the bandwidth is drastically increased. Figure 8 shows that the comparison of simulated and measured gain plot, which shows that gain, varies from 1.8 to $3.9 \mathrm{~dB}$ and it maintains nearly constant gain but less than $5 \mathrm{~dB}$, which confirms that the measured patterns are Omni-directional. The maximum radiation of this antenna is $92.9 \%$ at $2 \mathrm{GHz}$ and varies between $64.3 \%$ to its maximum value between the frequencies 2 to $15 \mathrm{GHz}$ that is shown in Figure 9. Therefore, the proposed antenna is the suitable one for UWB applications.

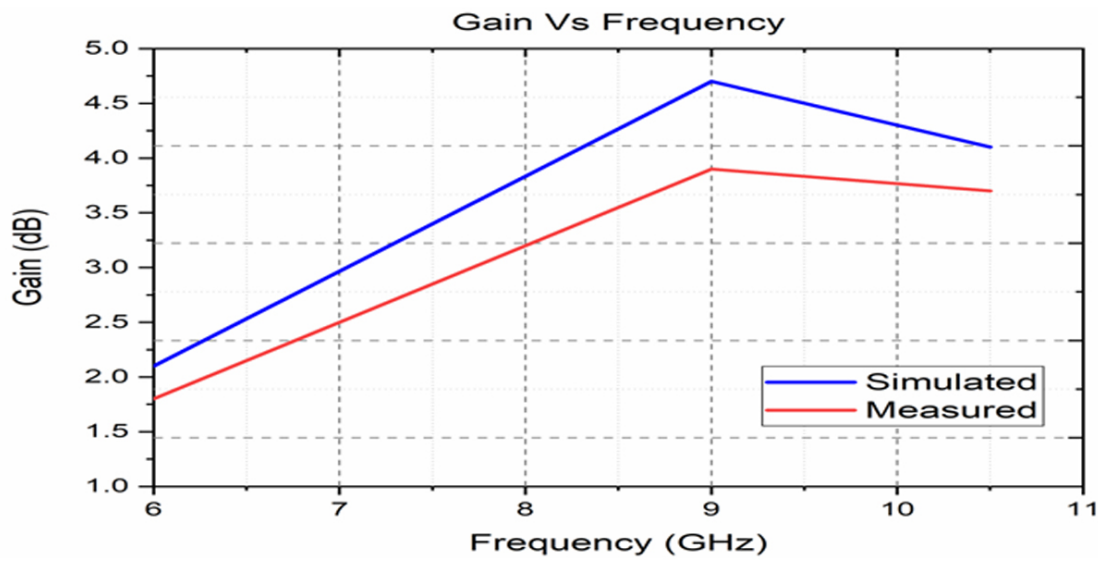

Fig 8. Comparison plot of simulated \& measured gain values 


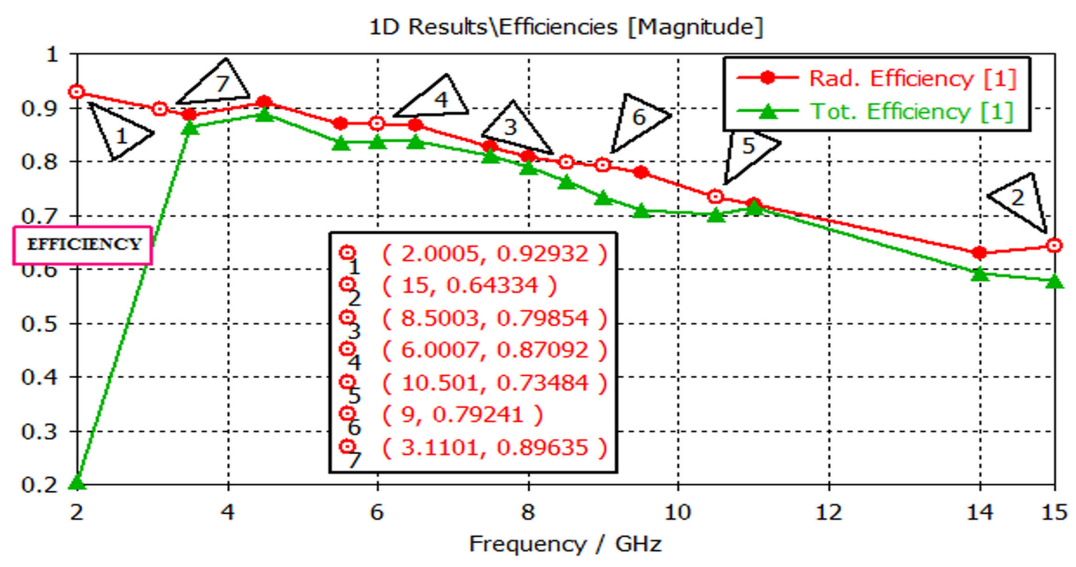

Fig 9. Radiation efficiency of proposed antenna (Simulation results)

Table 4. Comparison of Proposed antenna with some of the existing Antennas in the References.

\begin{tabular}{|c|c|c|c|c|c|}
\hline Ref. & $\begin{array}{l}\text { Antenna } \\
\text { Size }(\mathbf{W} \times \mathbf{L} \times \mathbf{h}), \mathbf{m m}^{3}\end{array}$ & $\begin{array}{l}\text { Substrate }+ \text { Ground }+ \\
\text { Feed types }\end{array}$ & $\begin{array}{l}\text {-10dB Operating Range(-10 } \\
\text { dB B.W }) \mathrm{GHz}\end{array}$ & $\begin{array}{l}\text { F.B.W } \\
(\%)\end{array}$ & Gain(dB) \\
\hline 3 & $36 \times 34 \times 1.6$ & FR-4+D.G.S ${ }^{1}+$ M.F.L ${ }^{2}$ & $3.5-14.9(11.4)$ & 123.91 & 5 \\
\hline 4 & $30 \times 35 \times 1.6$ & FR-4+D.G.S ${ }^{1}+$ M.F.L & $3.42-11.7(8.28)$ & 109.5 & 6 \\
\hline 5 & $36 \times 34 \times 1.6$ & FR-4+P.G.P+M.F.L & $3-10.26(7.26)$ & 109.5 & 5 \\
\hline 6 & $45 \times 45 \times 1.565$ & FR-4+D.G.S+M.F.L & $2.08-6.64(4.56)$ & 104 & 5.4 \\
\hline 7 & $50 \times 25 \times 0.17$ & $\begin{array}{l}\text { Foam+D.G.S+Coaxial } \\
\text { feed }\end{array}$ & $1.82-3.02(1.2)$ & 49.09 & 3 \\
\hline 8 & $38 \times 48 \times 1.6$ & FR-4+P.G.P+M.F.L & $2.5-10.6(8.1)$ & 123.6 & 8.4 \\
\hline 10 & $47 \times 30 \times 1.64$ & FR-4+D.G.S+M.F.L & $4.395-10.184(5.789)$ & 79.4 & 3.84 \\
\hline 11 & $17.59 \times 30 \times 1.6$ & FR-4+D.G.S+M.F.L & $2.66-10.82(8.16)$ & 121 & 3.38 \\
\hline 12 & $24 \times 24 \times 1.6$ & FR-4+P.G.P+M.F.L & $3.53-11.64(8.11)$ & 106.92 & 7.2 \\
\hline 13 & $37 \times 30.8 \times 1.6$ & FR-4+P.G.P+M.F.L & $2.08-3.99(1.91)$ & 62.9 & 4.7 \\
\hline 14 & $40 \times 40 \times 1.6$ & $\begin{array}{l}\text { Glass } \\
\text { Epoxy+P.G.P+M.F.L }\end{array}$ & $2.093-6.105(4.012)$ & 97.88 & 6.725 \\
\hline 15 & $42 \times 43.5 \times 1$ & $\begin{array}{l}\text { Jeans } \\
\text { Textile+D.G.S+M.F.L }\end{array}$ & $4.8-9(4.2)$ & 60.86 & 5.19 \\
\hline 17 & $29 \times 28 \times 1.6$ & FR-4+D.G.S+M.F.L & $5.73-10.8(5.07)$ & 61.34 & 6 \\
\hline 19 & $35 \times 35 \times 1.6$ & FR-4+D.G.S+M.F.L & $2.3-12.8(10.5)$ & 139 & 5 \\
\hline 22 & $25 \times 25 \times 1.6$ & FR-4+D.G.S+M.F.L & $2.9-11.5(8.6)$ & 119.4 & 8 \\
\hline $\begin{array}{l}\text { Proposed } \\
\text { Antenna }\end{array}$ & $30 \times 35 \times 1.6$ & FR-4+P.G.P+M.F.L & $2-15(13)$ & 152.9 & $\begin{array}{l}4.69 \text { (simulated) } \\
3.98 \text { (measured) }\end{array}$ \\
\hline
\end{tabular}

D.G.S ${ }^{1}=$ Defected Ground structure

M.F.L ${ }^{2}=$ Microstrip Feed Line

P.G.P ${ }^{3}=$ Partial Ground Plane

\section{Conclusion}

A corner defected multi-resonant UWB patch with a partial ground plane was designed, simulated and analyzed by CST and compared with the experimental results. This antenna yields a wide spectrum of $13 \mathrm{GHz}$ i.e. 2-15 GHz which includes UWB, WiMAX, C and X-band (8-12.4 GHz).This antenna has given a return loss of $<-10 \mathrm{~dB}$, VSWR of less than 2 throughout the operating band. The antenna almost maintains a consistent gain within the operating frequency and is less than $5 \mathrm{~dB}$. This antenna radiates multi resonance and Omni-directional radiation characteristics. Therefore, the proposed antenna is suitable for UWB, WiMAX, C, X-band and lower portion of $\mathrm{K}_{u}$ band applications. 


\section{References}

1) Federal communications commission. First report and order, revision of part 15 of the commission's rules regarding ultra wideband transmission systems, 02-48,ET Docket 98-153.. 2002.

2) Grag R, Bhartia P, Bahl I, Ittipiboon A. Microstrip antenna design handbook. Norwood, USA. Artech House. 2001.

3) Ahmed W, Amle SF, Awad NM, Abdelazeez MK. UWB antenna with corners modified patch. IEEE Jordan Conference on Applied Electrical Engineering and Computing Technologies. 2017;p. 11-13. doi:10.1109/ AEECT.2017.8257745.

4) Awad NM, Abdelazeez MK. Multislot microstrip antenna for ultra-wide band applications. Journal of King Saud University - Engineering Sciences. 2018;30(1):38-45. Available from: https://dx.doi.org/10.1016/j.jksues.2015.12.003.

5) Mazhar M, Tarar MA, Tahir FA, Ullah S, Bhatti FA. Compact microstrip patch antenna for ultra wideband applications. In: PIERS Proceedings. 2013;p. $1100-1104$.

6) Bakar HA, Rahim RA, Jack SP, Isa SR. Ultra-wideband Antenna with Slotted Ground Structure for Wireless Application. Journal of Physics: Conference Series. 2021;1878(1):012070-012070. Available from: https://dx.doi.org/10.1088/1742-6596/1878/1/012070.

7) Elias BBQ, Soh PJ, Al-Hadi AA, Akkaraekthalin P, Vandenbosch GAE. Bandwidth Optimization of a Textile PIFA with DGS Using Characteristic Mode Analysis. Sensors. 2021;21(7):2516-2516. Available from: https://dx.doi.org/10.3390/s21072516.

8) Gopi D, Vadaboyina AR, Dabbakuti JRKK. DGS based monopole circular-shaped patch antenna for UWB applications. SN Applied Sciences. 2021;3(2):112. Available from: https://dx.doi.org/10.1007/s42452-020-04123-w.

9) Sharmila1 D, Rao MP, Subbarao PSV, Bhavanam SN, , , et al. Design of a Multiband Octagonal Patch Antenna. Indian Journal of Science and Technology. 2019;12(3):1-6. Available from: https://dx.doi.org/10.17485/ijst/2019/v12i3/141596.

10) Sohi AK, Kaur A. Computational analysis of a dual-port semi-circular patch antenna combined with Koch curve fractals for ultra-wideband systems. Engineering Reports. 2021;3(9). Available from: https://dx.doi.org/10.1002/eng2.12378.

11) Saida I, Samira C, Layla W, Yassini AE, Zeroual A, Hassini MM. A pentagonal shaped microstrip planar antenna with defected ground structure for ultra wideband applications. Research Square. 2021;p. 1-16. Available from: https://doi.org/10.21203/rs.3.rs-506950/v1.

12) Verma RK, Srivastava DK. Bandwidth Improvement of Stub Loaded Compact Ultra-Wideband Microstrip Patch Antenna for C/X-Band Applications. Wireless Personal Communications. 2021;120(1):185-202. Available from: https://dx.doi.org/10.1007/s11277-021-08441-z.

13) Tripathi D, Srivastava DK, Verma RK. Bandwidth Enhancement of Slotted Rectangular Wideband Microstrip Antenna for the Application of WLAN/WiMAX. Wireless Personal Communications. 2021;2021:1-15. Available from: https://dx.doi.org/10.1007/s11277-021-08257-x.

14) Gupta A, Srivastava DK, Saini JP, Verma RK. Comparative analysis of microstrip-line-fed gap-coupled and direct-coupled microstrip patch antennas for wideband applications. Journal of Computational Electronics. 2020;19(1):457-468. Available from: https://dx.doi.org/10.1007/s10825-019-01416-1.

15) Yadav A, Singh VK, Mohan H. Design of a U-shaped circularly polarized wearable antenna with DGS on a fabric substrate for WLAN and C-band applications. Journal of Computational Electronics. 2019;18(3):1103-1109. Available from: https://dx.doi.org/10.1007/s10825-019-01342-2.

16) Mdn R, Mdt I, Singh J, Misran MS, Mat N, K, et al. Compact microstrip patch antenna for multi service wireless communications. In: Proceedings of 2017 Asia Pacific Microwave Conference. 2017;p. 13-16. doi:10.1109/APMC.2017.8251633.

17) George N, Lethakumary B. A compact microstrip antenna for UWB applications. Microwave and Optical Technology Letters. 2015;57:621-624. Available from: https://dx.doi.org/10.1002/mop.28910.

18) Shakib MN, Moghavvemi M, Mahadi WNL. A low-profile patch antenna for ultrawideband application. IEEE Antennas and Wireless Propagation Letters. 2015;14:1790-1793. Available from: https://dx.doi.org/10.1109/lawp.2015.2423931.

19) Ali T, Subhash BK, Pathan S, Biradar RC. A compact decagonal-shaped UWB monopole planar antenna with truncated ground plane. Microwave and Optical Technology Letters. 2018;60:2937-2944. Available from: https://dx.doi.org/10.1002/mop.31448.

20) Baudha S, Kumar VD. Corner truncated broadband patch antenna with circular slots. Microwave and Optical Technology Letters. 2015;57:845-849. Available from: https://dx.doi.org/10.1002/mop.28968.

21) Shrivastava MK, Gautam AK, Kanaujia BK. An M-shaped monopole-like slot UWB antenna. Microwave and Optical Technology Letters. $2014 ; 56: 127-131$. Available from: https://dx.doi.org/10.1002/mop.28057.

22) Shrivastava MK, Gautam AK, Kanaujia BK. A novel a-shaped monopole-like slot antenna for ultrawideband applications. Microwave and Optical Technology Letters. 2014;56:1826-1829. Available from: https://dx.doi.org/10.1002/mop.28458.

23) Haitham A. Design of a compact monopole antenna for wireless applications. In: International Conference on Advances in Computing and Communication Engineering. Paris, France. 2018. doi:10.1109/ICACCE.2018.8458050.

24) Yadav MVSB. A novel design of a planar antenna with modified patch and defected ground plane for ultra wideband applications. Microwave and Optical Technology Letters. 2019;p. 1-8. doi:10.1002/mop.31716.

25) Sudhakar AAK. Design and analysis of a compact coplanar waveguide fed ground slotted corner truncated ultra wideband patch antenna. In: International Conference on Vision Towards Emerging Trends in Communication and Networking. 2019. doi:10.1109/ViTECon.2019.8899379. 